\title{
O envelhecimento da população brasileira: um enfoque demográfico
}

\author{
The aging process in the Brazilian population: \\ a demographic approach
}

José Alberto Magno de Carvalho ${ }^{1}$

Ricardo Alexandrino Garcia ${ }^{1}$

\footnotetext{
1 Centro de Desenvolvimento e Planejamento Regional, Faculdade de Ciências Econômicas, Universidade Federal de Minas Gerais. Rua Curitiba 832, Belo Horizonte, $M G$ 30170-120, Brasil. carvalho@cedeplar.ufmg.br rica@cedeplar.ufmg.br
}

\begin{abstract}
Contrary to common sense, the population aging process is due to the decline in fertility rather than mortality. The aging process began around the end of the 19th century in a number of Western European countries, expanded to the rest of the so-called First World over the past century, and reached several Third World countries afterwards, including Brazil over the last decades. In the Brazilian case, a sharp and widespread fertility decline began by the end of the 1960 s, and an accelerated population aging process can thus be expected. This process will necessarily be faster and with deeper structural changes, demographically speaking, than in First World countries, for two reasons: the fertility decline in Brazil was faster, and it took place in a population with a younger age structure.
\end{abstract}

Key words Aging; Demography; Demographic Analysis

Resumo Contrariamente ao indicado pelo senso comum, o processo de envelhecimento populacional, tal como observado até hoje, é resultado do declínio da fecundidade, e não da mortalidade. O envelhecimento populacional iniciou-se no final do século XIX em alguns países da Europa Ocidental, espalhou-se pelo resto do Primeiro Mundo, no século passado, e se estendeu, nas últimas décadas, por vários países do Terceiro Mundo, inclusive o Brasil. No caso brasileiro, observou-se, a partir do final dos anos 60, rapidíssima e generalizada queda da fecundidade, e haverá, conseqüentemente, um célere processo de envelhecimento da população. Este processo será, necessariamente, mais rápido e com mudanças estruturais, demograficamente falando, mais profundas do que nos países do Primeiro Mundo por duas razões: o declínio da fecundidade, no País, deu-se em um ritmo maior e origina-se de uma população mais jovem do que aquela dos países desenvolvidos.

Palavras-chave Envelhecimento; Demografia; Análise Demográfica 


\section{Introdução}

Este artigo tem três objetivos principais: (1) mostrar, do ponto de vista puramente demográfico, qual o processo que leva ao envelhecimento de uma população; (2) analisar o processo de envelhecimento da população brasileira, levando em consideração apenas as mudanças recentes de sua dinâmica demográfica, já comprovadas; (3) comparar o processo brasileiro com o ocorrido na Europa, tomando a Inglaterra como exemplo, já amplamente documentado e conhecido, e que transcorreu com razoável anterioridade àquele ora observado no Brasil.

\section{A lógica demográfica no processo de envelhecimento populacional}

De início, há de se discutir alguns conceitos que, em muito, ajudam o entendimento sobre o tema em pauta. É importante diferenciar aumento de longevidade e envelhecimento de uma população.

Longevidade refere-se ao número de anos vividos por um indivíduo ou ao número de anos que, em média, as pessoas de uma mesma geração ou coorte viverão, definindo-se como geração ou coorte o conjunto de recém-nascidos em um mesmo momento ou mesmo intervalo de tempo.

No caso desta análise, interessa o conceito de longevidade, referido às pessoas de uma mesma geração. O total de recém-nascidos, em uma determinada unidade de tempo, experimentará, através dos anos vindouros, uma função de mortalidade, isto é, um conjunto de taxas específicas de mortalidade (TEM), por idade, até que o último sobrevivente morra. Denotese como $\ell_{o}$ esse total de recém-nascidos, e como $\ell_{x}$, o número deles que completa a idade exata $x$. Do ponto de vista empírico, não se conhece $\mathrm{o}$ valor de $\ell$ para toda e qualquer idade $\mathrm{x}$ exata. Geralmente, os valores de $\ell$ são conhecidos, ou estimados, para as idades exatas $1,2,3$, 5,10 e demais múltiplos de 5 , até uma idade avançada $\mathrm{x}$ a partir de 70 anos, dependendo das informações disponíveis. Introduz-se, então, uma nova anotação, ${ }_{n} \mathrm{~L}_{\mathrm{x}}$, que corresponde ao número de pessoas/ano, de uma determinada coorte, entre as idades exatas $\mathrm{x}$ e $\mathrm{x}+\mathrm{n}$, ou ao número total de anos que os sobreviventes da geração, que completarem a idade $\mathrm{x}$, viverão entre esta idade e a idade exata $x+n$. Por exemplo, se $\ell_{o}=100.000$ (número de recémnascidos de uma coorte) e se ${ }_{5} \mathrm{~L}_{20}=420.000$, isto significa que, dos 100.000 recém-nascidos, haverá 420.000 pessoas/ano, entre as idades exatas 20 e 25, ou que aqueles que alcançarem a idade exata de 20 anos viverão, conjuntamente, 420.000 anos entre essa idade e o 25 o aniversário.

Ao se somarem todos os valores de ${ }_{n} L_{x}$, tem-se o total de anos vividos pelos indivíduos de uma determinada coorte, desde o nascimento, até que o último indivíduo morra. Este total global é representado por $\sum_{x=0}^{\alpha} L_{x}$, que, dividido pelo número de nascimentos que deu origem à geração, $\ell_{o}$, fornece a esperança de vida, ao nascer, da coorte, ou a longevidade média, ao nascer, da geração. Em demografia, a esperança de vida ao nascer é representada por $e_{o}$, que é igual a $\sum_{x=0}^{\alpha} L_{x} / \ell_{0}$.

Duas coortes com a mesma esperança de vida ao nascer $\left(\stackrel{o}{e}_{o}\right)$, ou longevidade média ao nascer, podem estar submetidas a duas funções de mortalidade completamente diferentes, de modo que, por exemplo, em uma haja maiores TEM nas primeiras idades do que na outra, e, nesta, maiores TEM nas idades adultas ou avançadas, de tal maneira que, no cômputo geral, gerem efeitos que se compensam perfeitamente, em termos de $\stackrel{o}{e}_{o}$. Neste caso, diz-se haver mesmo nível de mortalidade, porém com padrões diferentes. Na primeira geração, obviamente, uma proporção maior de seus componentes que chegarem à idade adulta alcançará as idades mais avançadas, vis-à-vis os componentes da segunda geração. No entanto, nas duas coortes haverá a mesma longevidade média ao nascer.

Uma outra maneira de se considerar a longevidade é tomar a idade média em que morrerão aqueles indivíduos que alcançarem a idade correspondente à ${ }_{o}$. Neste caso, a longevidade média $=\stackrel{o}{e}+\frac{\sum_{x=y}^{\alpha} n L_{x}}{\ell_{y}}$, onde $y=\stackrel{o}{e}$.

Ao se adotar este conceito, e não o anterior, está-se dando maior peso, ao se comparar a longevidade de populações ou coortes diversas, à sobrevivência nas idades mais avançadas. Adotado este conceito, no exemplo anterior a primeira coorte teria uma longevidade média maior do que a segunda. Ambas têm a mesma $\stackrel{o}{e}_{o}$, porém, na primeira, a mortalidade é menor nas idades avançadas.

O envelhecimento populacional não se refere nem a indivíduos, nem a cada geração, mas, sim, à mudança na estrutura etária da população, o que produz um aumento do peso relativo das pessoas acima de determinada idade, considerada como definidora do início da velhice. Este limite inferior varia de sociedade para sociedade e depende não somente de fa- 
tores biológicos, mas, também, econômicos, ambientais, científicos e culturais, não cabendo, aqui, maior discussão sobre o tema. Neste trabalho, toma-se a idade de 60 anos como o divisor entre idosos e não-idosos.

Supondo-se uma população fechada, sua estrutura etária, composta por indivíduos pertencentes a inúmeras gerações, dependerá, em qualquer momento, apenas de dois fatores: (1) o tamanho inicial, número de nascidos vivos de cada geração, ocorrido $\mathrm{x}$ anos atrás, sendo $\mathrm{x}$ a idade atual dos indivíduos, e (2) a função de mortalidade a que esses indivíduos estiveram submetidos entre o nascimento e a idade $\mathrm{x}$.

Em uma situação hipotética, em que o número anual de nascimentos seja constante, a diferença entre o número de pessoas, em duas idades distintas, será totalmente explicada pela mortalidade. Se, ademais, estiverem submetidas à mesma função de mortalidade (conjunto de TEM, por idade), a coorte mais velha será menor do que a outra, simplesmente por ter estado, por mais tempo, exposta à mortalidade.

Chama-se essa população de estacionária. Caracteriza-se por ter função de mortalidade constante, função de fecundidade constante, tais que, combinadas, produzem um número anual de nascimentos constante e igual ao número de óbitos. Tal população tem crescimento nulo. Nesse caso, cada coorte de mulheres dá à luz um número de filhas igual ao tamanho inicial da geração das mães, havendo perfeita reposição. Para que isto aconteça, a taxa de fecundidade total (TFT - número médio de nascidos vivos, nascidos por mulher, ao final de seu período reprodutivo -) deve ser em torno de 2,1.

Para facilidade de argumentação, pense-se em uma população com função de mortalidade constante, mas na qual, a cada ano, o número de nascimentos seja maior do que o do ano anterior, segundo uma taxa constante. Neste caso, o número de pessoas nas idades mais jovens será maior do que nas idades mais velhas, não somente pelo menor tempo de exposição à mortalidade, mas, também, por ter se originado de uma coorte de nascimentos maior. Se, por exemplo, a coorte de idade exata 10 vier de um número de nascimentos $\mathrm{N}$, as crianças que nascem agora, neste exato momento, serão $\mathrm{N}$ e 10.r, onde $\mathrm{e}=$ número neperiano, $\mathrm{r}=\mathrm{a}$ taxa anual de crescimento do número de nascimentos. Conseqüentemente, dada a mesma função de mortalidade, uma população será tanto mais jovem, quanto maior for o ritmo de crescimento do número anual de nascimentos, isto é, quanto maior for seu nível de fecundidade.

Uma população fechada, mantidas constantes as funções de fecundidade e mortalida- de, qualquer que seja a estrutura etária inicial, necessariamente tenderá a uma estrutura etária constante, com taxa de crescimento também constante. A essa população se chama de estável. A população estacionária é um caso especial de população estável, com taxa de crescimento zero (UN, 1970).

Equivocadamente, muitos pensam que a baixa mortalidade é responsável pela grande proporção de idosos nos países do Primeiro Mundo. Na verdade, o declínio da mortalidade, tal como o observado até agora, teve como efeito um rejuvenescimento das populações, e não seu envelhecimento. Isto, por duas razões: (1) proporcionalmente, a queda se concentrou mais nas idades mais jovens, o que, por si só, não teve impacto direto, a não ser a curto prazo, na distribuição etária proporcional; (2) ao propiciar, em cada coorte, um número maior de mulheres sobreviventes até o final do período reprodutivo, o declínio da mortalidade teve, como conseqüência, um número maior de nascimentos, o que, como visto, leva a uma proporção maior de jovens na população.

Haverá, sim, um maior envelhecimento da população como conseqüência do declínio da mortalidade, se este se concentrar nas idades avançadas, como, crescentemente, passa-se a prever para um futuro não muito distante (sobre o tema, veja o número especial da revista Population, sobre Biodemographic Perspectives on Human Longevity, lançado em 2001). Neste caso, não haveria impacto algum sobre o número de nascimentos, apenas um aumento do número absoluto de idosos, como proporção da população total.

Em vários países do Terceiro Mundo, inclusive o Brasil, entre os anos 30 e 60 do século XX, houve sensível declínio da mortalidade, com a fecundidade mantendo-se em níveis altos. No caso brasileiro, houve leve declínio da fecundidade no período (Frias \& Carvalho, 1994). Dado o padrão de queda da mortalidade, referido anteriormente, não houve impacto significativo na estrutura etária proporcional, somente sobre o ritmo de crescimento populacional, fenômeno conhecido, na época, como explosão demográfica. A essa situação se chama de quase-estabilidade (mortalidade declinante, fecundidade basicamente constante, taxas de crescimento crescentes e estrutura etária aproximadamente constante).

Ao se começar o declínio sustentado de fecundidade é que se dá início ao processo de envelhecimento de uma população. Em vários países, inclusive o Brasil, que, até então, tinham uma população extremamente jovem, quaseestável, com o declínio da fecundidade, o rit- 
mo de crescimento anual do número de nascimentos passou, imediatamente, a cair, o que fez com que se iniciasse um processo contínuo de estreitamente da base da pirâmide etária, conseqüentemente, de envelhecimento da população.

Em uma primeira etapa, após o início do declínio da fecundidade, passa-se por uma fase de desestruturação da distribuição etária relativa da população, por conviverem nela gerações nascidas quando a fecundidade era alta e aquelas que já sofreram o impacto da queda. Com o passar do tempo, tende-se a alcançar nova estabilidade na estrutura etária da população, quando todas aquelas coortes oriundas da alta fecundidade desaparecerem. Se a fecundidade, após o declínio, se estabilizar, a nova estrutura etária estável ou quase-estável a ser alcançada será bem mais envelhecida do que aquela de antes da queda da fecundidade. Isto porque a diferença entre o tamanho de uma geração e outra dependerá, além do maior tempo de exposição à mortalidade (tal como no período de alta fecundidade), da diferença do tamanho inicial das diversas gerações, agora muito menor, devido ao declínio da fecundidade.

\section{O envelhecimento da população brasileira}

Pode-se afirmar que até os anos 60, a partir, pelo menos, de 1940 (o censo anterior ao de 1940, foi o de 1920, que apresentou sérios problemas quanto à qualidade dos dados), a população brasileira apresentou-se como quase-estável, com distribuição etária praticamente constante. Era uma população extremamente jovem, com em torno de $52 \%$ abaixo de 20 anos, e menos de $3 \%$ acima dos 65 anos (Figura 1).

Nesse período, houve significativo declínio da mortalidade (a $\stackrel{o}{e}$ passou de aproximadamente 41 anos, na década de 30 , para 55,7 , anos, na década de 60 - Carvalho, 1974) e houve leve queda da fecundidade (a taxa de fecundidade total teria passado de 6,1 filhos por mulher, nos anos 30, para 5,8, em 1970 - Frias \& Carvalho, 1994). Parece que, como visto na seção anterior, o efeito rejuvenescedor do declínio da mortalidade foi perfeitamente compensado pelo efeito contrário da leve queda da fecundidade, permanecendo, assim, constante a estrutura etária da população. Obviamente, no período em questão houve significativa aceleração no ritmo de crescimento da população, que, de uma taxa anual de $2,4 \%$, na década de 40 , passou para $2,9 \%$, nos anos 60 .
No final da década de 60 , inicia-se rápido e generalizado declínio da fecundidade no Brasil. Sua TFT passa de 5,8, em 1970 (Carvalho, 1974), para algo em torno de 2,3 filhos, por mulher, em 2000. O nível da fecundidade, em 2000, já está bem próximo daquele de reposição, isto é, aquele que produz crescimento nulo da população a longo prazo. Parte da população já se encontra com fecundidade abaixo do nível de reposição e o nível médio do País deverá continuar a cair, pois há claras indicações de rápido declínio no Nordeste e em grupos mais pobres da população. Como conseqüência, entra a população brasileira em um sustentado processo de desestabilização de sua estrutura etária, com estreitamento continuado da base da pirâmide e, conseqüentemente, envelhecimento da população (Camarano, 1999; Wong, 2001) (Figura 2).

Vê-se, claramente, nas pirâmides da Figura 2 , a convivência de gerações nascidas antes e depois do rápido declínio da fecundidade, separadas em torno da idade de 10 anos, em 1970; de 20 anos, em 1991; 30 anos, em 2000.

A Tabela 1 apresenta a proporção de pessoas nos grupos etários de 0 a 14 anos, 15 a 60 anos e de 60 anos e mais, nos quatro últimos censos brasileiros. É evidente o rápido processo de envelhecimento, que só se estabilizará tempos após o término do declínio da fecundidade.

Se, a partir do ano 2000, não houver mais declínio da fecundidade no Brasil, o que é de todo improvável, mesmo assim continuará o processo de envelhecimento da população, até que desapareça, totalmente, de sua configuração etária, os efeitos diretos e indiretos da alta fecundidade do passado.

A Tabela 2 e a Figura 3 comparam a estrutura etária da população recenseada no ano 2000, com aquela da população estável que, necessariamente, será alcançada, se, a partir de 2000 , não houver mais mudança nas funções de mortalidade e fecundidade do Brasil (população estável, definida pelas funções de mortalidade e de fecundidade brasileiras do ano 2000). Como, provavelmente, a fecundidade continuará a cair (Wong, 2000), pode-se afirmar que a estrutura estável de 2000 define o grau de envelhecimento (proporção de idosos de 19,3\%) mínimo a ser atingido nas próximas décadas, supondo-se que a população brasileira permaneça fechada.

Necessária se faz uma última observação. Como o processo de envelhecimento se dá via declínio da fecundidade, ao se alcançar a estabilidade etária, no futuro, haverá, necessariamente, um número absoluto de idosos menor do que aquele que se teria na ausência de que- 
Figura 1

Distribuição proporcional (\%) da população por sexo e idade. Brasil, 1940, 1950, 1960 e 1970.
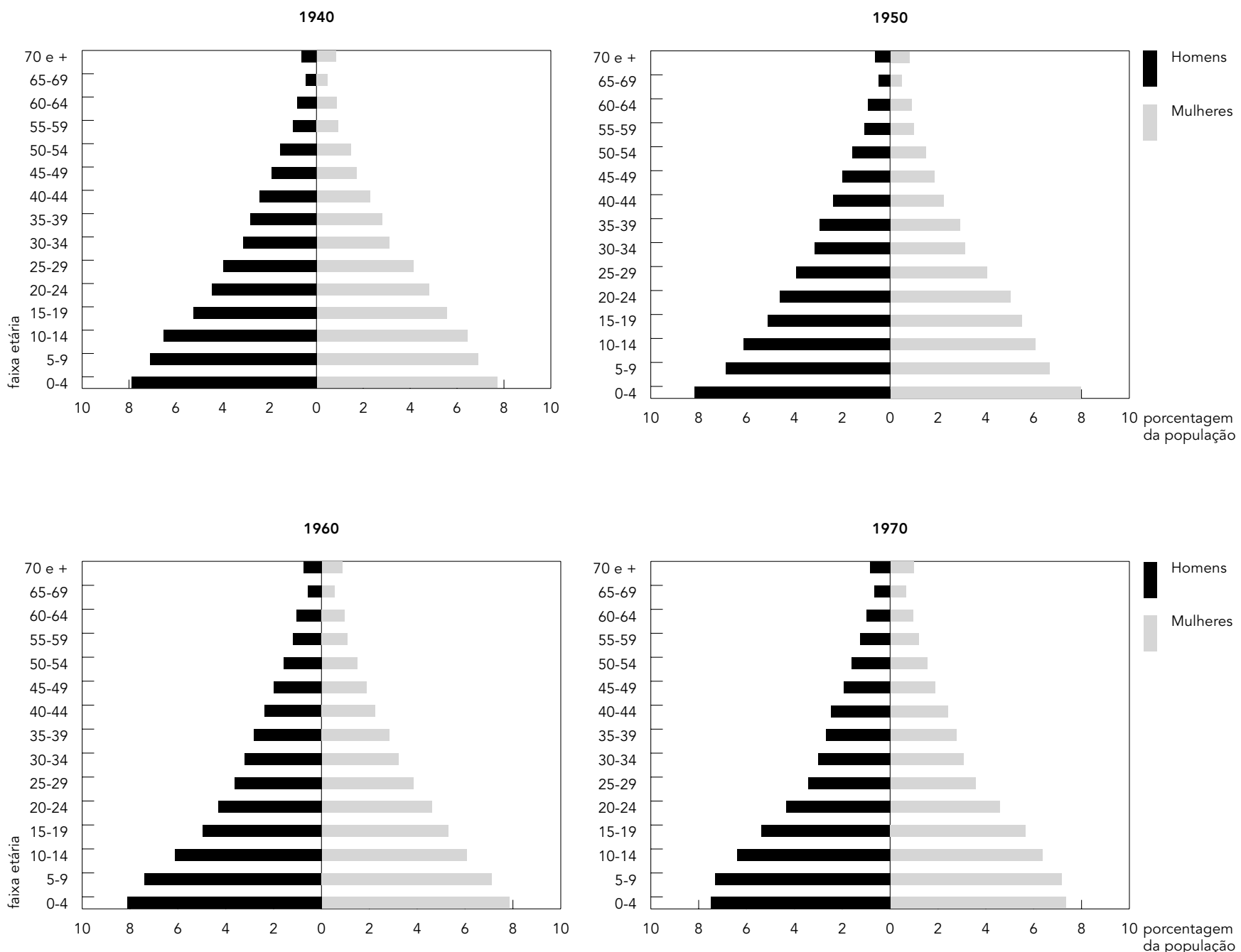

Fonte: IBGE $(1940,1950,1960,1970)$ 
Figura 2

Distribuição proporcional (\%) da população por sexo e idade. Brasil, 1980, 1991 e 2000.
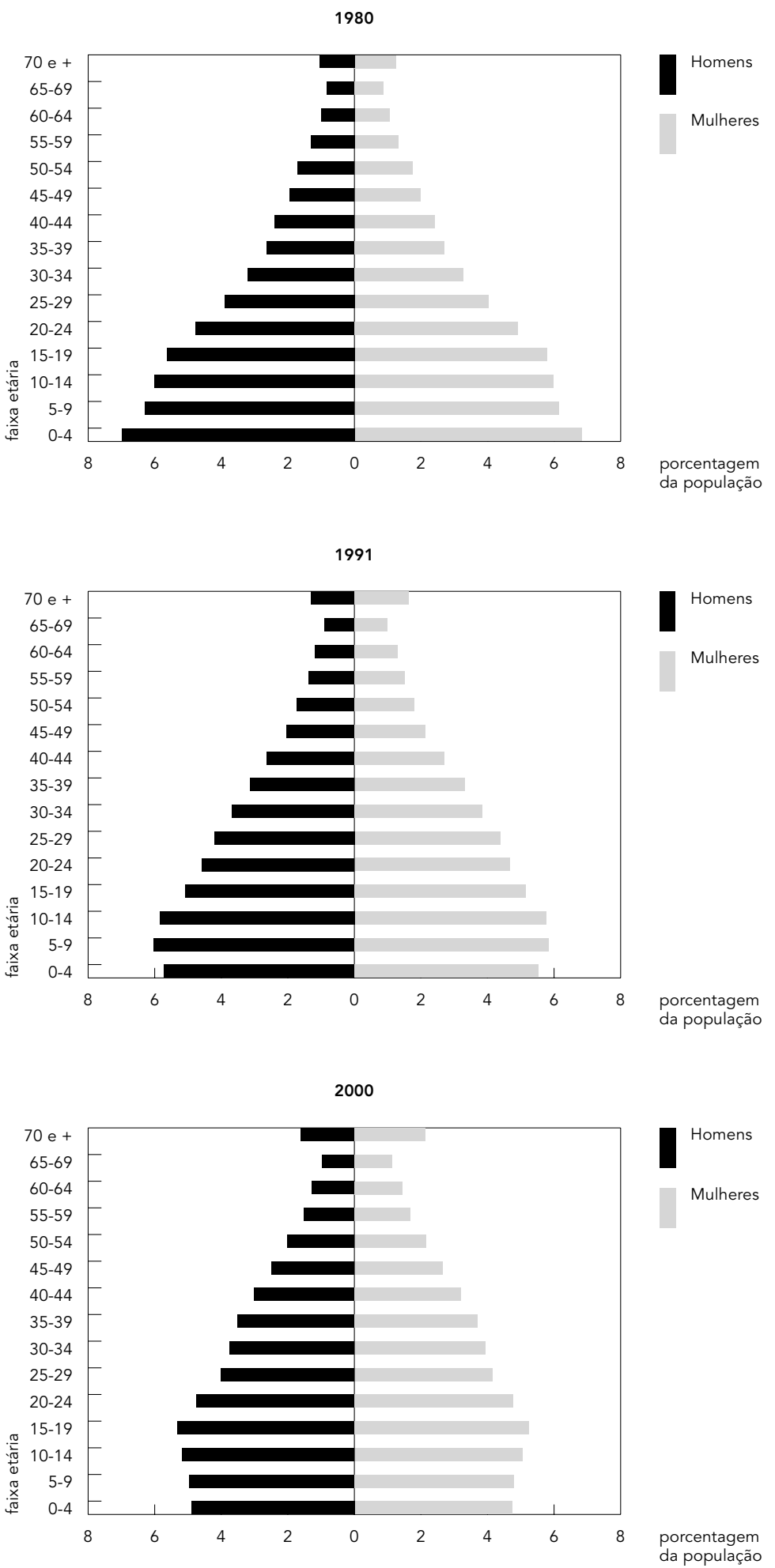

Fonte: IBGE (1980, 1991, 2000). da da fecundidade. Os problemas porventura advindos desse processo não estão relacionados ao número absoluto de idosos, mas, sim, a seu peso relativo na população total.

\section{O processo de envelhecimento no Brasil e a experiência da Inglaterra}

A transição da fecundidade, entendida como sua passagem de níveis altos para níveis baixos, foi primeiro observada e documentada em alguns países da Europa Ocidental, assim como sua conseqüência natural, o processo de envelhecimento da população.

Duas observações importantes, quando se deseja comparar aquele processo com o ora observado no Brasil:

- Antes do início do declínio da fecundidade naqueles países, na segunda metade do século XIX, ela se encontrava em patamares significativamente inferiores àqueles da fecundidade brasileira, ao iniciar seu rápido declínio, 100 anos depois;

- O declínio naqueles países europeus se deu de forma sustentada, porém a um ritmo bem menor do que o observado no Brasil, quando da transição de sua fecundidade.

Pelo exposto na segunda seção deste trabalho, pode-se afirmar, tendo em vista os dois pontos anteriores, que:

- As populações daqueles países europeus, antes do início do declínio da fecundidade e, conseqüentemente, de seu processo de envelhecimento, já tinham uma proporção de idosos maior do que a brasileira, ao iniciar o mesmo processo.

- O envelhecimento da população brasileira (variação relativa da proporção de idosos) se dará a um ritmo significativamente maior, se comparado com aquele já observado naqueles países europeus.

Para efeito de comparação, tome-se a Inglaterra, classificada entre os países europeus que tiveram o início de declínio da fecundidade já no século XIX. A Figura 4 mostra a evolução de seus níveis de fecundidade total, a partir de 1870, assim como os do Brasil, a partir de 1905. Enquanto a Inglaterra, partindo, em 1870, de um nível menor (TFT de 5,3), necessitou de 100 anos para ter um declínio de 58\% (TFT de 2,2, em 1970), o Brasil, nos 30 anos entre 1970 e 2000 , experimentou uma queda de $60 \%$, com sua TFT passando de 5,8 para 2,3 filhos nascidos vivos, por mulher.

Em virtude de, principalmente, seu menor nível de fecundidade, a Inglaterra já tinha, em $1870,7,4 \%$ de sua população total com 60 anos 
e mais de idade, proporção que, no Brasil, em 1970, correspondia a apenas $5,1 \%$ (Tabela 3 ). O peso relativo daqueles menores de 15 anos era $36,1 \%$ na Inglaterra, em 1870 , e $42,1 \%$ no Brasil, em 1970.

$\mathrm{Na}$ Inglaterra, 60 anos mais tarde, em 1930, a proporção de idosos passou para $11,6 \%$, isto é, um aumento de $56 \%$, enquanto, no Brasil, entre 1970 e 2000, um intervalo de 30 anos, cresceu em $69 \%$, passando de 5,1 para $8,6 \%$ da população.

A diferença entre os níveis de fecundidade do Brasil $(5,8)$ e Inglaterra $(2,3), 163 \%$ maior no primeiro, em 1970, passou para apenas $44 \%$, em 2000 (TFT de 2,3 e 1,6, respectivamente). A rápida convergência entre os níveis de fecundidade dos dois países fará, também, com que haja rápida convergência na proporção de população idosa. Em 2000, a proporção de idosos na Inglaterra era de $20,4 \%$, contra $8,6 \%$, no Brasil. Como visto, a proporção de idosos no Brasil alcançará, no mínimo, 19,3\%, na hipótese improvável de que não haja mais declínio de fecundidade no País.

\section{Conclusão}

Do ponto de vista puramente demográfico, o processo, ora em operação no Brasil, de envelhecimento da população deve-se, unicamente, ao rápido e sustentado declínio da fecundidade. Se, porventura, no futuro próximo, houver avanços em termos de queda significativa de mortalidade, concentrada nas idades avançadas, haverá aceleração do processo.

O envelhecimento da população brasileira se dará, necessariamente, a ritmo maior do que aquele ocorrido nos países do Primeiro Mundo, principalmente naqueles que iniciaram sua transição da fecundidade ainda no século XIX. Por outro lado, esses países, antes do início do processo, já conviviam com populações menos jovens, por nunca terem experimentado níveis tão altos de fecundidade quanto o Brasil.

A rapidíssima mudança na estrutura etária brasileira cria, para o País, oportunidades para o enfrentamento de alguns problemas básicos, principalmente relacionados às crianças e jovens, porém coloca novos desafios, gerados, mormente, pelo envelhecimento de sua população (Carvalho \&Wong, 1999). Não coube neste trabalho desenvolver essas questões, mas vale a pena, ainda que de passagem, enunciá-las.
Tabela 1

Brasil: distribuição proporcional (\%) da população, segundo grandes grupos etários - 1970, 1980, 1991 e 2000.

\begin{tabular}{lrrrr}
\hline Grupo etário (anos) & \multicolumn{4}{c}{ Ano do recenseamento } \\
& 1970 & 1980 & 1991 & 2000 \\
\hline $0-14$ & 42,10 & 38,24 & 34,73 & 29,60 \\
$15-59$ & 52,83 & 55,69 & 57,97 & 61,84 \\
60 e + & 5,07 & 6,07 & 7,30 & 8,56 \\
Total & 100,00 & 100,00 & 100,00 & 100,00 \\
\hline
\end{tabular}

Fonte: IBGE (1970, 1980, 1991, 2000).

Tabela 2

Brasil: 2000. Comparação da distribuição proporcional (\%) da população por grandes grupos etários, com sua respectiva população estável.

\begin{tabular}{lrrrrrr}
\hline $\begin{array}{l}\text { Grupo etário } \\
\text { (anos) }\end{array}$ & Total & $\begin{array}{c}2000 \\
\text { Homens }\end{array}$ & Mulheres & Total & $\begin{array}{r}\text { Estável } \\
\text { Homens }\end{array}$ & Mulheres \\
\hline $0-14$ & 29,60 & 30,52 & 28,72 & 22,16 & 23,26 & 10,87 \\
$15-59$ & 61,80 & 61,66 & 62,00 & 58,52 & 59,97 & 29,41 \\
60 e + & 8,60 & 7,82 & 9,28 & 19,32 & 16,77 & 21,73 \\
Total & 100,00 & 100,00 & 100,00 & 100,00 & 100,00 & 100,00 \\
\hline
\end{tabular}

Fonte: CEDEPLAR (1999); IBGE (2000).

Figura 3

Comparação da distribuição proporcional (\%) da população por sexo e idade, com sua respectiva população estável. Brasil, 2000.

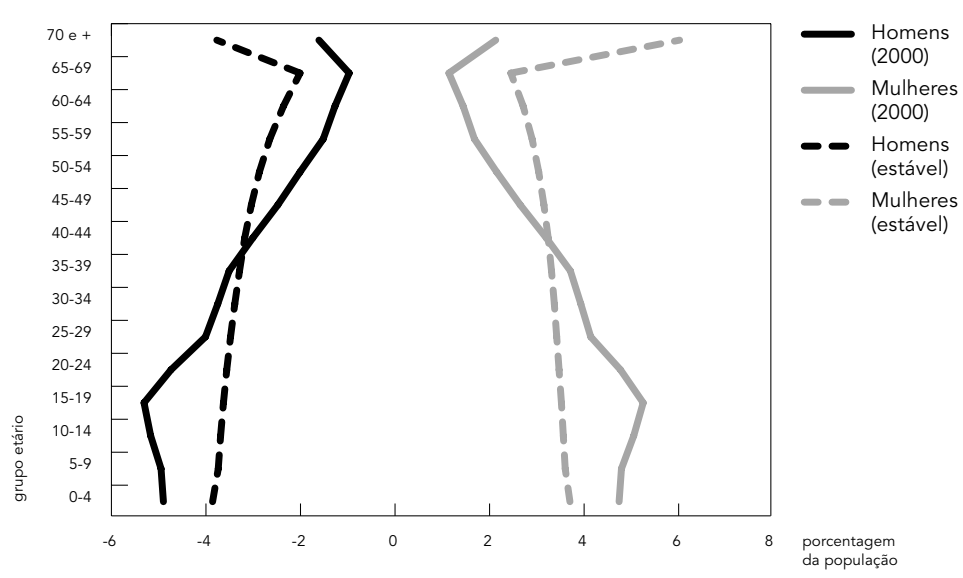

Fonte: CEDEPLAR (1999); IBGE (2000). 
Figura 4

Taxa de fecundidade total (TFT). Brasil e Inglaterra: vários anos.

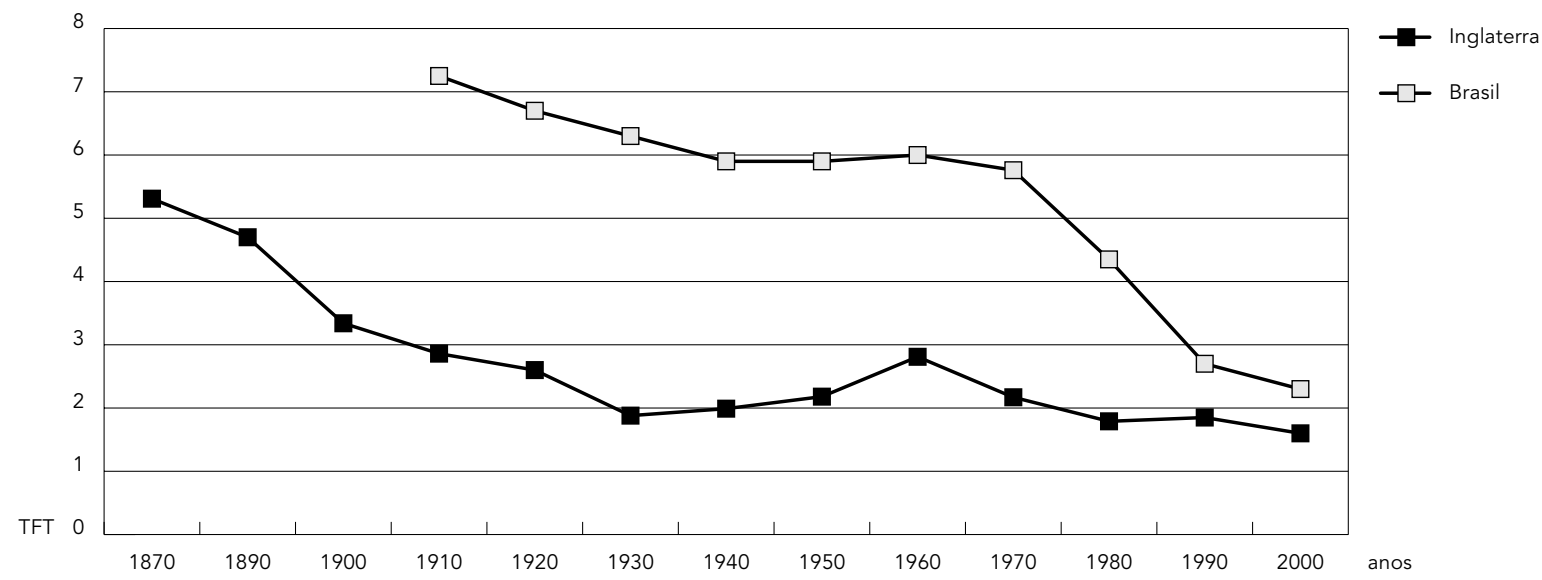

Fonte: 1870/1990 - Carvalho \& Wong (1999); 2000 - CEDEPLAR (1999) e United Kingdom National Statistics (2002).

Tabela 3

Brasil e Inglaterra: comparação da distribuição proporcional (\%) da população por grandes grupos etários - anos selecionados.

\begin{tabular}{|c|c|c|c|}
\hline \multirow[t]{2}{*}{ Grupo etário (anos) } & \multicolumn{3}{|c|}{$\begin{array}{c}\text { Inglaterra } \\
\text { Ano do recenseamento }\end{array}$} \\
\hline & 1870 & $1931^{*}$ & 2000 \\
\hline $0-14$ & 36,1 & 23,8 & 18,9 \\
\hline $15-69$ & 56,5 & 64,6 & 60,7 \\
\hline $60 e+$ & 7,4 & 11,6 & 20,4 \\
\hline Total & 100,0 & 100,0 & 100,0 \\
\hline Total absoluto (mil) & 21.000 & 39.952 & 49.997 \\
\hline \multirow[t]{2}{*}{ Grupo etário (anos) } & \multicolumn{3}{|c|}{$\begin{array}{c}\text { Brasil } \\
\text { Ano do recenseamento }\end{array}$} \\
\hline & 1940 & 1970 & 2000 \\
\hline $0-14$ & 42,6 & 42,1 & 29,6 \\
\hline $15-59$ & 53,3 & 52,8 & 61,8 \\
\hline $60 e+$ & 4,1 & 5,1 & 8,6 \\
\hline Total & 100,0 & 100,0 & 100,0 \\
\hline Total absoluto (mil) & 41.165 & 93.138 & 169.799 \\
\hline
\end{tabular}

Fonte: IBGE (1940, 1970, 2000); United Kingdom National Statistics (2002); UN (1948); Wrigley \& Schofield (1981). 


\section{Referências}

CAMARANO, A. A. (org.), 1999. Muito Além dos 60: Os Novos Idosos Brasileiros. Rio de Janeiro: Instituto de Pesquisa Econômica Aplicada.

CARVALHO, J. A. M., 1974. Regional trends in fertility and mortality in Brazil. Population Studies, 28: 401-421.

CARVALHO, J. A. M., 1993. Crescimento Populacional e Estrutura Demográfica no Brasil. Rio de Janeiro: Ministério do Exterior/Agência Brasileira de Cooperação.

CARVALHO, J. A. M. \& WONG, L., 1999. Demographic and socioeconomic implications of the rapid fertility decline in Brazil: A window of opportunity. In: Reproductive Change in India and Brazil (G. Martine, M. Gupta \& L. Chen, ed.), pp. 208-239, Oxford: Oxford University.

CEDEPLAR (Centro de Desenvolvimento e Planejamento Regional), 1999. Projeção Populacional das Unidades da Federação, Brasil, por Sexo e Grupos Qüinqüenais de Idades, 1990-2020. Belo Horizonte: CEDEPLAR, Universidade Federal de Minas Gerais. (mimeo.)

FRIAS, L. A. M. \& CARVALHO, J. A. M., 1994. Fecundidade nas regiões brasileiras a partir de 1903: Uma tentativa de reconstrução do passado através das gerações. In: Encontro Nacional de Estudos Populacionais, Anais, v. 2, pp. 23-46, Belo Horizonte: Associação Brasileira de Estudos Populacionais.

IBGE (Fundação Instituto Brasileiro de Geografia e Estatística), 1940. Censo Demográfico: Brasil, 1940. Rio de Janeiro: IBGE.

IBGE (Fundação Instituto Brasileiro de Geografia e Estatística), 1970. Censo Demográfico: Brasil, 1970. Rio de Janeiro: IBGE.

IBGE (Fundação Instituto Brasileiro de Geografia e Estatística), 1980. Censo Demográfico: Brasil, 1980. Rio de Janeiro: IBGE.

IBGE (Fundação Instituto Brasileiro de Geografia e Estatística), 1991. Censo Demográfico: Brasil, 1991. Rio de Janeiro: IBGE.
IBGE (Fundação Instituto Brasileiro de Geografia e Estatística), 2000. Censo Demográfico: Brasil, 2000. Rio de Janeiro: IBGE.

MOREIRA, M. M., 1997. Envelhecimento da População Brasileira. 1997. Tese de Doutorado, Belo Horizonte: Centro de Desenvolvimento e Planejamento Regional, Universidade Federal de Minas Gerais.

UN (United Nations), 1948. Demographic Yearbook. New York: United Nations Department of Economic and Social Affairs.

UN (United Nations), 1970. El Concepto de Población Estables: Aplicación a el Estudios de las Poblaciones de Países que no Tienen Buenas Estadísticas Demográficas. New York: Department of Economic and Social Affairs.

UNITED KINGDOM NATIONAL STATISTICS, 2002. 2000 - Based Population Projections for the United Kingdom and Constituent Countries. 7 April 2002 <http://www.gad.gov.uk/population/2000/ prinres.html>.

WONG, L. R., 2000. A projeção da fecundidade: Um exercício aplicado ao Brasil para o período 1991 2020. In: Encontro Nacional de Estudos Populacionais. Brasil, 500 anos: Mudanças e Continuidades. CD-ROM. Recife: Associação Brasileira de Estudos Populacionais.

WONG, L. R. (org.), 2001. O Envelhecimento da População Brasileira e o Aumento da Longevidade: Subsídios para Políticas Orientadas ao Bem-Estar do Idoso. Belo Horizonte: Centro de Desenvolvimento e Planejamento Regional/Universidade Federal de Minas Gerais/Associação Brasileira de Estudos Populacionais.

WRIGLEY, E. A. \& SCHOFIELD, R. S., 1981. The Population History of England 1541-1871. London: Edward Arnold.

Recebido em 8 de maio de 2002

Versão final reapresentada em 6 de fevereiro de 2003

Aprovado em 27 de fevereiro de 2003 